\title{
A "ESPORTIVIZAÇÃO" DA ESCOLA NA SOCIEDADE DO ESPETÁCULO: O CASO DOS JOGOS DA PRIMAVERA EM SERGIPE (1964-1995)
}

\author{
Hamilcar Silveira Dantas Junior* \\ Universidade Federal de Sergipe
}

\section{RESUMO:}

Ao longo do século XX, marcado pelos signos do espetáculo, o esporte, como produção histórico-cultural da modernidade pautada na institucionalização de temas lúdicos da cultura corporal, foi apropriado como saber a ser escolarizado no âmbito dos projetos educacionais modernos. Todavia, esse projeto de "escolarização do esporte" transmutou-se em projeto de "esportivização da escola" devido à confluência de um movimento histórico internacional que radicava uma cultura moderna, jovem e espetacular, reconstruindo as tradições escolares aos moldes da sociedade do espetáculo. No Brasil, tal processo teve suas peculiaridades regionais que, em Sergipe, foram materializadas nos Jogos da Primavera, evento esportivo-educacional luminar do Estado no período de 1964 a 1995. Os Jogos tornaram-se a referência das concepções acerca de esporte e educação física em todo o Estado. O objetivo deste trabalho é investigar como os Jogos da Primavera tornaram-se o epicentro da "esportivização da escola" ou a síntese educacional da sociedade do espetáculo: a contínua reconstrução das tradições ritualísticas esportivas em espetáculo, com a ênfase no caráter mercantil do esporte, inebriando o seio escolar com sua lógica de produtividade e selecionamento.

Palavras-chave: esporte; jogos estudantis; tradição; espetáculo.

\section{THE "SCHOOL SPORTING" IN THE SOCIETY OF THE SPECTACLE: THE CASE OF THE “JOGOS DA PRIMAVERA” IN SERGIPE (1964 TO 1995).}

\begin{abstract}
:
Throughout the twentieth century, marked by signs of the spectacle, the sport, as historical and cultural production of modernity based on the institutionalization of topics entertainment of body culture, has been know to be appropriate in the context of school art education projects. However, this project of "sport schooling" transmute it into a project of "school sporting" because of the confluence of a movement rooted history that an international modern culture, young and spectacular, reconstructing the traditional school mold to society of the spectacle. In Brazil, it has its regional peculiarities that in Sergipe, were materialized in the "Jogos da Primavera", luminary educational sporting event of the State in the period 1964 to 1995. The Games have become the reference of conceptions of sport and physical education throughout the State. The objective of this study is to investigate how the "Jogos da Primavera" have become the epicenter of the "school sporting" or the educational synthesis of the spectacle society: the continuous rebuilding of sport ritual traditions into spectacle, with emphasis in the commercial character of the sport, stunning the school environment with its logics of productivity and selection.

Key words: sport; student games; tradition; spectacle.

A educação física em Sergipe - não obstante todos os debates acadêmicos acerca de sua especificidade pedagógica e relevância educacional originados nos anos 1980, bem como as condições objetivas de intervenção didática — tem como parâmetro histórico de inserção escolar o evento esportivo conhecido como Jogos da Primavera.
\end{abstract}


Por habitar os recônditos da memória social é possível à minha geração lembrar algumas daquelas tardes de sábado no mês de setembro, ao longo da década de 80 . Em toda a extensão da Avenida Barão de Maruim, no centro da cidade de Aracaju, milhares de pessoas iam se aglomerando em suas calçadas. Vindas de diversos pontos da cidade, inclusive de vários municípios do interior do estado, a população parecia deslocar-se toda para essa região. Trafegavam a pé, de automóvel, sobretudo de ônibus, tendo em vista que nesse dia, linhas exclusivas eram disponibilizadas para o povo. Esse ia se misturando aos vendedores ambulantes, policiais, bombeiros, agentes de saúde, distribuidores de panfletos políticos, e às autoridades políticas abancadas em um palanque no centro da avenida.

Com isso a avenida coloria-se, mudava o aspecto sisudo do cotidiano, para dar passagem às cores e aos sons das escolas sergipanas, mas, essencialmente, dar passagem aos anseios e desejos de jovens estudantes, pais, diretores escolares e professores que seriam aquecidos nesse dia: o dia do desfile de abertura dos Jogos da Primavera. Desejos e anseios canalizados ao longo dos próximos doze ou quinze dias nas competições esportivas, a serem realizadas em diversos pontos da cidade.

Nos dias seguintes, num raio de dois quilômetros no centro do "quadrado de Pirro" ${ }^{1}$, a juventude explodia em sua movimentação frenética na busca pelos palcos de disputas esportivas. Os ginásios Charles Moritz e Constâncio Vieira, os clubes do Cotinguiba, Associação Atlética de Sergipe, Iate Clube, Vasco, Clube do Trabalhador, o Estádio Estadual Lourival Baptista e o Parque Aquático do Batistão eram os espaços onde as competições de futebol, futebol de salão, basquetebol, handebol, voleibol, tênis, judô, ginásticas rítmica e artística, natação, pólo aquático, saltos ornamentais se desenrolavam, materializando as perspectivas e desejos construídos por professores, alunos e pais ao longo de todo o ano letivo. Estavam abertos oficialmente, os Jogos da Primavera do Estado de Sergipe (doravante referenciados como Jogos), evento esportivo institucionalizado que reunia em disputa as escolas das redes estadual, municipal, federal e particular de ensino, sob a égide do congraçamento e com objetivos "sócio-educativos".

Era sob esse cenário que os sergipanos viviam intensamente seu mais importante acontecimento esportivo-estudantil. Um evento que mobilizava alterações nas suas rotinas escolar, familiar, política, econômica e cultural. Todos os olhares voltavam-se aos Jogos, conformando a vida da cidade de Aracaju à sua realização.

No desfile dos Jogos e nas competições podiam-se observar as radicais diferenças entre escolas particulares e públicas: no desfile luxuoso, no vestuário, no material esportivo, na postura dos atletas, na relação alunos e professores, no trato da arbitragem. De igual modo, percebia com estranheza a reverência feita aos políticos que se punham no palanque do desfile e vinham entregar medalhas e troféus no encerramento dos Jogos.

De maneira geral, os Jogos tornaram-se a referência das concepções acerca de esporte e educação física em todo o Estado, estabelecendo, no âmbito da formação dos professores, uma visão dicotômica entre aqueles que os vislumbram como o ápice da educação física e aqueles que percebem uma série de problemas a reboque do evento, afetando o sistema educacional em sua totalidade. Os Jogos da Primavera de Sergipe realizados de modo irregular no período de 1964 a 1995 (retomados a partir de 2004), portanto, constitui-se aqui, um objeto de estudo com recortes espacial e temporal próprios, inserindo-se na interseção entre história e memória, entre o que é fato e o que é representação do fato.

Nesse feixe de circunstâncias diversas, defendo que os Jogos enraizaram-se na memória coletiva das últimas gerações, dentre as quais faço parte. Considero, com base em Paul Connerton (1999), que as nossas experiências do presente dependem de nosso conhecimento e das imagens que trazemos do passado, transmitidos e conservados em 
performances mais ou menos rituais. Nesse enraizamento memorialístico, as cerimônias comemorativas e as práticas corporais são elementos centrais ao que o autor denomina de "sedimentação da memória social corporal". A educação, em sua forma escolar, e o esporte são práticas fundantes e solidificadoras dessa memória; e eventos como os Jogos, que imbricam os objetivos educacionais e a catarse esportiva, se consubstanciam no fulcro do conflito entre os interesses ditos e silenciados, mostrados e ocultos, os anseios externados e aprisionados. É nesse processo que os homens se movem, em um jogo entre regras e burlas, entre desejos, realizações e frustrações.

Uma relação intercontextual entre esporte e escola exige um diálogo, jamais um monólogo diretivo de uma instituição sobre a outra. Isso posto, percebe-se que, ao longo do último século, houve todo um processo conflituoso de incorporação do esporte como um bem cultural a ser escolarizado. Entendendo escolarização, segundo a indicação de Vago (2003), por duas vias. Primeiro, a consecução de processos e políticas de organização de redes institucionais responsáveis pelo ensino formal. Segundo, a escola, ou a forma escolar, ressaltada como espaço de socialização e transmissão de conhecimentos, de articulação de sentidos e significados. $\mathrm{O}$ esporte, por conseguinte, enquanto manifestação cultural rica de caracteres simbólicos, tornou-se um saber a ser escolarizado. Tal dimensão histórica fincou raízes nas Public Schools da Inglaterra de fins do século XIX, onde os passatempos, divertimentos e jogos se converteram em práticas institucionalizadas, denominadas desportos, daí exportados em escala global como avanço civilizatório. Utilizo o termo "esportivização" para designar a substancial passagem do esporte, nas aulas de educação física, de conteúdo escolarizado a conteúdo exclusivo, passando então, a gerador de uma nova forma de organizar o conhecimento, os espaços, tempos e relações sociais dentro e fora da escola.

Tais dimensões de escolarização e esportivização só se consubstanciam pela ação humana efetiva. Portanto, compreendo que é na experiência e pela experiência que os sujeitos se constituem, indivíduos ou classes sociais. A escola é um campo fértil às múltiplas possibilidades de experimentação e o esporte um espaço, ao mesmo tempo fraterno e tenso, de convívio e construção de concepções de mundo. Para Edward Thompson (1981, p. 189),

[...] as pessoas não experimentam sua própria experiência apenas como idéias, no âmbito do pensamento e de seus procedimentos, ou (como supõem alguns praticantes teóricos) como instinto proletário, etc. Elas também experimentam sua experiência como sentimento e lidam com esses sentimentos na cultura, como normas, obrigações familiares e de parentesco, e reciprocidades, como valores ou (através de formas mais elaboradas) na arte ou nas convicções religiosas.

$\mathrm{Na}$ tradição historiográfica da educação física, as análises da relação entre escolarização e esportivização apontam para o total controle do Estado e do mercado sobre a educação física, limitando a ação dos professores às suas determinações. Entendo, conforme Taborda de Oliveira (2003), que tais estudos enfatizam a direção política, mas não as experiências e contradições, inerentes ao processo histórico, entre as determinações e as ações. $\mathrm{O}$ que me leva a algumas ponderações. Os professores podem ter se mantido alheios e reproduzido os interesses políticos vigentes ou mesmo estabelecido alguns graus de oposição aos mesmos. Os professores também podiam ter clareza de tais interesses ou não. Considerando que houve ênfase do Estado para o desenvolvimento do esporte na consecução da escola como base da pirâmide esportiva e aceitando a tese de que as ações 
dos professores convergiram nessa direção, é fato que não nos tornamos uma "nação olímpica"2.

Para intelectuais como Bracht (1992) e Coletivo de Autores (1992), havia a intenção e a consecução de um prolongamento da instituição esportiva na escola, implantando-se o "esporte na escola", sem construir as possibilidades do "esporte da escola". Essa tinha as suas funções redimensionadas aos cânones da instituição esportiva: rendimento, competição, comparação de resultados, regulamentação rígida, sucesso como sinônimo de vitória no esporte, racionalização de meios e técnicas. $\mathrm{O}$ esporte nas aulas de educação física foi canalizado como finalidade, não como meio, portanto a aprendizagem limitava-se às técnicas esportivas e à incorporação de suas normas. A escola não conseguiria mais discutir o esporte, recriá-lo, desenvolver valores assentados no coletivismo, pensar a integração do corpo discente sem seleção dos melhores, enfim, a escola tornou-se incapaz de criar um "esporte da escola", com base em suas características e necessidades culturais.

Entendo que tais conclusões acerca da instituição do "esporte na escola" são generalizantes, totalizantes e não consideram a pluralidade de espaços, sujeitos e práticas escolares. Os espaços escolares no Brasil, notadamente no sistema público de ensino, em sua imensa maioria, não comportam tratar o esporte em seus códigos de rendimento, dadas as impossibilidades físicas, materiais e humanas. Mesmo reconhecendo o impacto do ambiente espetacularizado da modernidade, impondo o esporte como único saber a ensinar na educação física, a realidade escolar torna imperioso que professores e alunos, no afã de quererem tematizar o esporte ou mesmo montar suas equipes escolares, cotidianamente reelaborem as práticas, adaptem-nas e recriem-nas, construindo, dia a dia, "esportes da escola".

O esporte, não obstante, tornou-se o conteúdo praticamente exclusivo da educação física. A "esportivização" da escola se deu - na escola particular pela prática e na escola pública pelo desejo da prática - pela confluência de um movimento histórico internacional que radicava uma cultura moderna, jovem e espetacular, reconstruindo as tradições aos moldes do espetáculo. Compreendo que tais reflexões/inquietações, atinentes ao processo de "esportivização" da sociedade, em pleno vigor das relações espetaculares, incidem diretamente sobre o Estado de Sergipe na condução da política educacional, das relações entre educação física e esporte nos jogos escolares, sobretudo na ação efetiva dos professores.

O objetivo deste trabalho, fruto dos meus estudos de Doutoramento, é ilustrar como os Jogos, em Sergipe, foram alçados de uma dimensão de "escolarização do esporte" a um dos epicentros de "esportivização da escola", ou seja, notadamente no âmbito das escolas privadas, ratificou uma lógica de mercantilização da educação e da educação física sob os auspícios dos símbolos imagéticos de relações sociais cada vez mais espetacularizados.

\section{I - Os Jogos da Primavera (1964-1978): as tentativas de escolarização}

Conforme já aludido, os Jogos da Primavera é o evento esportivo-educacional que referencia a educação física no Estado de Sergipe, por habitar a memória dos professores e da sociedade como a representação franca da vivacidade, talento e nacionalidade da juventude sergipana ${ }^{3}$. Compreendendo o evento como de larga expressão social, na tentativa de visualização de suas contradições na materialização da memória social, principalmente dos professores de educação física sergipanos, classifico-o metaforicamente, afinal, falamos de esporte em três fases: Iniciação (1964-1967), Aperfeiçoamento (1970-1978) e Treinamento (1979-1995) . 
A primeira fase é de Iniciação ou de primeiros contatos com uma organização que envolve múltiplos fatores econômicos, sociais, políticos e culturais, mas, tacitamente, começa a tratar, de modo institucionalizado com a organização esportiva, seguindo os cânones de um evento reconhecido nacionalmente, os Jogos da Primavera do Jornal dos Sports no Rio de Janeiro. Esse movimento esportivo, iniciativa pioneira do jornalista Mário Rodrigues Filho, proprietário do Jornal dos Sports, reunia os grandes clubes e as grandes escolas da cidade em verdadeiras maratonas olímpicas. Para Boccardo (1998), sua materialização consolidou o esporte como movimento social integrador, marcou um processo de democratização desta prática para a mulher e solidificou a mídia esportiva, como a principal impulsionadora do esporte. Os Jogos da Primavera do Rio de Janeiro tornaram-se a grande fonte inspiradora para Sergipe.

Essa primeira fase compreende o período dos quatro primeiros Jogos (1964-1967). Seu surgimento é um híbrido de interesses entre o governo do estado de Sergipe, personificado no Secretário interino de Estado da Educação Curt Vieira, com apoio de José Carlos Marques, professor paulista de educação física, contratado pelo governo para incrementar a educação física no estado no ano de 1963, e as demandas práticas dos estudantes universitários de iniciativa do Presidente da Federação Atlética dos Estudantes de Sergipe (FAES), Raimundo Monte.

Os Jogos foram realizados com esforços de vários segmentos da comunidade aracajuana. O Governo do estado dava total apoio à sua realização, cedendo os espaços, organizando o desfile de abertura, inscrevendo escolas da rede estadual. A imprensa oferecia ampla cobertura nos impressos e nas Rádios. As casas comerciais apressavam-se em oferecer troféus e medalhas aos competidores.

As três primeiras edições dos Jogos reuniram as escolas superiores do estado, escolas estaduais, federais e particulares situadas na capital. A partir da IV edição, as escolas superiores já não participaram, provocando uma cisão enfraquecedora no processo. Diante desse grupo de escolares, entendo que, nessa fase, solidificou-se a memória social em torno da representação do esporte ${ }^{5}$. O desfile de abertura pelas ruas do Centro de Aracaju, com carros alegóricos, tocha olímpica, juramento do atleta, comissão julgadora da mais bela exposição escolar no desfile são ilustrativos desse momento, além da escolha da mais bonita estudante-atleta dos Jogos, a "Rainha da Primavera". A reprodução peculiar dos rituais olímpicos enraíza o princípio de identificação com o passado, via tradição, consolidando a memória por via das performances.

Os Jogos nas quatro primeiras edições resultaram no plantio de uma semente de escolarização do esporte por via do enraizamento de uma tradição, crescentemente espetacularizada. A cidade de Aracaju precisava de espaços esportivos. As escolas precisavam de professores qualificados. Os diretores enxergaram no evento uma grande vitrine para suas escolas, sejam de natureza privada ou pública, ou para mostrarem-se coniventes aos rumos políticos. A imprensa representou o evento como uma grande matriz de notícias com múltiplas interfaces, dedicando-lhes amplos espaços nas primeiras páginas. Os alunos divertiram-se, confraternizaram-se, brigaram e viveram o caráter multifacetado do esporte. A classe política enxergou um grande espetáculo de aproximação ao povo, de divulgação de realizações e de encenação eleitoreira (DANTAS JUNIOR, 2008).

Após as quatro edições iniciais, criou-se um hiato entre 1968 e 1970, pois não é realizado nenhum torneio esportivo de alcance estadual, envolvendo os estabelecimentos educacionais. Não obstante, começou-se a plantar a semente do desenvolvimento da educação física e do esporte no Estado: cursos de formação de professores de educação física, construção de escolas, estádios e ginásios. No ano de 1970, o Governo do Estado era ocupado pelo Sr. João Andrade Garcez e a Secretaria de Educação e Cultura (SEC) pelo 
Sr. Nestor Piva. Este anunciava, em julho desse ano, que os Jogos da Primavera seriam retomados. Aqui se inicia a segunda fase: o Aperfeiçoamento, que se estende de 1970 a 1978 no qual ocorreram nove edições dos "Jogos Estudantis Sergipanos" (JES).

No plano oficial, o Estado amplia as iniciativas normativo-legais: formação de comissão organizadora, comissão de relações públicas, procedimentos do desfile de abertura, regulamento dos JES e suspensão das aulas em todas as escolas, não somente as participantes, durante o período de realização dos mesmos. Fato a destacar nessa fase, o nome dos Jogos, que o Secretário Nestor Piva pretendia reeditar, foi alterado para "I Jogos Estudantis Sergipanos". A constituição é similar, mas qual o motivo da alteração do nome? Por que inaugurar nova contagem, desconsiderando as edições anteriores dos Jogos da Primavera? Um elemento aparece como indicativo para esta alteração: a criação e realização no ano de 1969 dos "I Jogos Estudantis Brasileiros" (JEBs) $)^{6}$. Tal iniciativa delegou aos Estados da Federação, a responsabilidade de selecionar os atletas que os representariam na peleja nacional. O processo de "esportivização" da escola ganhava um reforço oficial, tornando os jogos escolares um campo de "garimpagem" de talentos esportivos, assim como um ambiente propício à sua instrumentalização política.

Considerando esses aspectos, insiro os "Jogos Estudantis Sergipanos" na fase de Aperfeiçoamento, não apenas pelas iniciativas legais, mas pelo ambiente favorável à consecução de uma memória social em torno da "Nação", através do esporte. A conquista do tricampeonato mundial de futebol, no México, e os investimentos e ações do governo ditatorial federal para o esporte, nessa década, são ilustrativos de uma ambiência identificadora com o nacionalismo, via espetáculo imagético.

As nove edições dos "Jogos Estudantis Sergipanos" revelaram um aumento substancial, ano a ano, da participação de escolas sergipanas. Sem a atuação das Escolas Superiores, os "Jogos Estudantis" ampliaram seu alcance com alunos de escolas de todo o estado, não mais só da capital. Essa fase me parece descortinar uma reconstrução mais radical entre as tradições - unidade social entre esporte e escola; anseios de desenvolvimento do país - e o espetáculo, esporte como "vitrine" de homens, principalmente graças à chegada das redes de televisão e suas transmissões esportivas ${ }^{7}$.

Todavia, diferentemente do que o senso comum afirma - "a ditadura investiu maciçamente no esporte escolar" —, tal fato não se consubstanciou em realidade. Revelei alhures (DANTAS JUNIOR, 2008), que a falta de investimento massivo nos JES, a desmotivação da população em participar das cerimônias, a representação dos mesmos nos jornais locais, agora relegados às pequenas notas, diferentes das manchetes de primeira página dedicadas na década anterior aos Jogos da Primavera, revelam o distanciamento entre intenção e realização, entre o discurso e a prática, entre o fato e as interpretações do fato. Os JES, idealizados para acompanhar a proposta dos JEBs de tornar a escola o espaço de formação da elite esportiva nacional, distanciou-se gradativamente, ao longo desses anos, das possibilidades de realização de seu intento.

De igual modo, enquanto os JEBs dedicavam-se a estruturar moldes científicos para a detecção de talentos esportivos, em Sergipe, os JES jamais estabeleceram quaisquer normas de avaliação e seleção de atletas. As escolhas dos técnicos das modalidades representantes nos JEBs ou eram políticas, indicadas pela SEC e federações esportivas, ou eram baseadas no estatuto da autoridade acadêmica quando eram indicados os professores de Educação Física da UFS. A seleção dos atletas era pautada em critérios técnicos subjetivos, de autoria dos treinadores indicados, sem qualquer planejamento científico.

Germinavam as condições para a "esportivização" da escola, todavia o que aconteceu foi apenas um ensaio do que viria mais à frente. $\mathrm{O}$ "aperfeiçoamento" resultou eficiente para passar ao "treinamento", no entanto, tal passagem se daria com outro nome e 
ideário ao engendrar-se uma nova jogada de reconstrução das tradições e radicalização do espetáculo.

\section{II - A "esportivização da escola": a escola como clube}

Após assumir, em 1979, o governo do estado, indicado pela Presidência da República, o usineiro Augusto Franco nomeou Secretário de Estado da Educação, o Sr. Antônio Carlos Valadares, ex-prefeito do município de Simão Dias, ex-deputado estadual e à época eleito deputado federal. Uma trajetória política meteórica no partido da ditadura, a Aliança Renovadora Nacional (ARENA). Na administração da Educação, o secretário Valadares incentivou o esporte amador, encampou o projeto de retorno dos Jogos da Primavera e ratificou uma tradição política brasileira, principalmente de raízes oligárquicas: desconsiderar as realizações de governos anteriores.

Ao longo dos anos subseqüientes, criar-se-ia uma personificação do secretário Valadares como "idealizador/criador" e principal incentivador dos Jogos. Todavia, a tentativa de personalização, ou de realização da démarche política, sobre os Jogos não permitiu a seus realizadores o cuidado necessário concernente à continuidade da tradição. Os Jogos foram retomados em 1979 com a numeração de IV (4º) Jogos da Primavera. Com essa medida, relegou-se ao ostracismo histórico e à memória de alguns indivíduos a realização, em 1967, dos IV Jogos da Primavera; única edição que, na $1^{\text {a }}$ fase, foi vencida por uma escola pública, o Atheneu, à época Colégio Estadual de Sergipe ${ }^{8}$. Os Jogos recomeçavam com uma contagem equivocada que, ao contrário de ratificar uma tradição, reorganizou outra sob os auspícios dos donos do poder.

Por conseguinte, a terceira fase que visualizo compreende o período de 1979-1995, do ressurgimento dos Jogos da Primavera à sua última edição. Esse é o período de consolidação ou do Treinamento. Aqui se atinge o ápice da institucionalização esportiva escolar, dado o apogeu da representatividade social dos Jogos, sua garantia de empregabilidade e de ação pedagógica dos professores de educação física, além de grande vitrine publicitária das escolas particulares que vinculavam as vitórias esportivas às vitórias na vida, culminando com seu súbito encerramento em 1995.

As ações oficiais do governo de Sergipe ao longo da década de 80, principalmente no âmbito da "Nova República", serão praticamente voltadas ao esporte no seio escolar, não mais à educação física: Fundo de Promoção e Desenvolvimento de Esportes (1979), Projeto de Desenvolvimento do Desporto Escolar (1985), Projeto de Desenvolvimento do Esporte para Todos (1985), Projeto de Desenvolvimento do Esporte Escolar (1986), Projeto de Desenvolvimento da Prática Esportiva (1986), Projeto de Desenvolvimento do Esporte na Escola (1987) ${ }^{9}$. As justificativas de resgate dos Jogos e a organização dos mesmos, num misto entre o discurso tradicional de congraçamento dos indivíduos e o discurso moderno de fortalecimento das federações esportivas, refletirão a consolidação da instituição esportiva na escola.

Entendo que, para além da tensão temporal entre o tradicional e o moderno, as justificativas de retorno dos Jogos, nesse momento, revelam o imbricamento entre o particular e o geral, o local e o internacional. O movimento olímpico internacional e seus discursos relativos ao desenvolvimento econômico e social dos países, via oferta de trabalhos e modernização urbana, da unificação nacional, bem como da solidificação das instituições esportivas expressam seu alcance e penetração em todos os países do globo, sobretudo pela difusão em massa via televisão. Guardadas as peculiaridades locais, Sergipe não ficou infenso a esse discurso motivador, o Estado aos benefícios políticos e as escolas particulares aos benefícios sociais e econômicos que poderiam advir da instrumentalização esportiva. 
Contudo, numa fase de Treinamento, a contenda se estabelece, tendo em vista que os opositores também estão "treinando". Se o Estado apontava para a educação física a direção exclusiva do esporte enquanto prática orientadora de sua ação pedagógica, em Sergipe, alguns professores se apropriaram de uma "leitura crítica" da educação física, que se opunha à "esportivização" escolar e começaram a tecer duras críticas aos objetivos, andamento e representação dos Jogos. De igual modo, apontavam práticas pedagógicas diferenciadas, imersas no discurso renovador da educação física e resistente aos rumos políticos que tomavam os Jogos. Estabeleceu-se uma diferenciação clara no corpo docente de educação física do estado de Sergipe: de um lado, os professores da disciplina/atividade educação física; do outro, os professores de esporte, o que resultou inclusive em ferrenhos debates que sempre desembocavam na questão de ser "contra" ou "a favor" do esporte na escola.

Conforme Dantas Junior (2008), este foi um momento de tensão. Enquanto o governo investia nos Jogos da Primavera, a situação da escola pública refletia a fragmentação da profissão docente entre professores e treinadores, a existência de parcos materiais para as práticas esportivas e a absoluta ausência de material para as aulas de educação física. De igual modo, os professores apontaram direções diferenciadas de trato com a educação física, sobretudo na esteira de novidades educacionais como a Psicomotricidade, além de engajarem-se, junto à Associação dos Profissionais do Magistério do Estado de Sergipe (APMESE), em críticas e resistências ao modelo posto.

Tais tensões revelaram que as concepções explodiam em todos os seus contrastes e contradições, mas se opunham em pólos distintos: a defesa dos Jogos, por parte dos professores de esporte, "órfãos" desde o seu encerramento em 1995, dos diretores de escolas particulares que tinham os Jogos como grande "vitrine" dos seus estabelecimentos, e da classe política que instrumentalizava o evento com fins de aceitação popular; e a posição contrária aos Jogos, em sua forma e conteúdo, por parte dos professores de educação física, impregnados do discurso de tendências críticas da educação, construindo práticas alternativas, que passaram a enxergá-los como grande óbice ao desenvolvimento da área no estado.

Os Jogos da Primavera de Sergipe, portanto, têm se configurado de modo ambivalente. Por um lado, expressam (ou iludem) visualmente o desenvolvimento do esporte escolar. Por outro, plasmam a concepção de educação física como esporte e tornam a educação física, enquanto um componente curricular, refém de práticas extracurriculares.

Nesse contexto, em meio à "crise" da educação física, o desenvolvimento do pensamento renovador e a construção das práticas cotidianas da área, que iam do uso pedagogizado do esporte ao seu uso exclusivo para seleção de atletas, era notório que o ritmo acelerado da sociedade do espetáculo massificaria o esporte como bem mercadorizado e gestaria, inclusive oficialmente, a "esportivização" da escola.

Considerando que escolas e clubes têm finalidades diferenciadas, tal fato foi negligenciado pela Secretaria de Educação Física do MEC ao estabelecer as normas para organização e funcionamento do desporto escolar, tornando-o autônomo da área que o deveria pedagogizar, a educação física. A Portaria n. ${ }^{\circ} 1$, de 7 de abril de 1982, instituiu que o desporto escolar ou as atividades esportivas praticadas no ensino de $1^{\circ}$ e $2^{\circ}$ graus, integrava tanto o Sistema Educacional do país, quanto o Sistema Desportivo Nacional. Com esta junção atribuiu-se aos órgãos educacionais dos Estados, a função de planejar e realizar eventos esportivos escolares, selecionar e preparar atletas e equipes para representação em competições nacionais. Pari passu, instituiu uma excrescência educativa, 
contudo uma dádiva aos princípios mercantis da educação, o "Clube Escolar" (BRASIL, 1982).

$\mathrm{O}$ "clube escolar" era representado pelo estabelecimento de ensino e vinculado às secretarias de educação e federações esportivas, devendo estimular o esporte via atividades extra-classe e competições interescolares. Os "atletas escolares" seriam todos os alunos do estabelecimento, reconhecidamente aptos e que poderiam participar de treinamentos esportivos visando à especialização e à melhoria dos resultados. Os "técnicos desportivos escolares" seriam profissionais legalmente habilitados, preferencialmente professores de educação física e, no caso de sua inexistência, poderiam ser, pasmem, leigos. Nas "competições desportivas", sob a coordenação das secretarias de educação, as modalidades olímpicas deveriam receber tratamento prioritário. Finalmente, o diretor da escola seria o "Presidente nato do Clube Escolar".

Entendo que a escola é o espaço de socialização, democratização e acúmulo do conhecimento historicamente sistematizado. As atividades, em seu seio, são sistematizadas no que convencionamos denominar de currículo, ou as atividades nucleares da escola, fundamentais à formação humana, conforme afirma Saviani (1995). Isso posto, atividades extracurriculares só se justificam atreladas a essa concepção, e suportes às atividades nucleares. A educação física, enquanto componente curricular, pressupõe que sua participação na formação dos jovens se deva a um saber a ser sistematizado, a ser escolarizado, na forma de jogos, danças, ginásticas, lutas e esporte. A tentativa de tornar o esporte uma atividade extracurricular que se sobreponha à estrutura curricular, um serviço a ser comprado, limitando sua participação a uma elite estudantil, naturalizando e incorporando seus códigos de seletividade e especialização e orientando a dinâmica escolar sob tais códigos significa a opção da escola por se "esportivizar". Com as bênçãos oficiais do MEC e a promoção de jogos escolares nos moldes dos JEBs e dos Jogos da Primavera, alimentou-se tal perspectiva na escola pública e tornou a escola particular o espaço que "deu certo", dessa tendência de "esportivização".

Após a publicação da Portaria e com a solidificação dos Jogos, 11 escolas públicas se inscreveram nos "IX" Jogos da Primavera como "Clube Escolar"10. Qual a dimensão educativa dessa proposta? Que rumos esportivos poderiam ser trilhados diante de condições físicas e materiais precárias? A proposição das escolas públicas como "clube escolar" não se repetiu nos Jogos seguintes. As escolas voltaram à sua triste realidade, o que significou, a partir de 1985, a condição de meros coadjuvantes do apogeu da "profissionalização" do esporte escolar das escolas privadas.

Conforme apontei, as escolas privadas tornaram-se hegemônicas nos resultados dos Jogos, lançando toda sorte de estratagemas para tal: falsificação de documentos dos alunos, compra de resultados, "contratação" de "atletas" de escolas públicas. De modo destacado, ainda que não comprovadamente envolvido neste esquema de falsificações, o Colégio Arquidiocesano Sagrado Coração de Jesus tornou-se a referência da "esportivização" da escola personificada no apoio ao esporte, dado pelo seu diretor, o Padre José Carvalho de Souza.

José Carvalho de Souza, nascido no município de Lagarto, tornou-se seminarista no Seminário Diocesano de Aracaju, formando-se em Humanidades e Filosofia na Paraíba e em Pernambuco. Ordenou-se Padre em 1956 e foi indicado Reitor do Seminário Menor Sagrado Coração de Jesus. Em 1960, eminente educador que era, fundou o Ginásio Diocesano que se tornaria o Colégio Arquidiocesano Sagrado Coração de Jesus, uma das maiores referências educacionais da sociedade sergipana (FIGUEIREDO, [198-]).

De matriz religiosa, o Arquidiocesano jamais poderia descuidar do equilíbrio necessário entre "corpo e espírito", o que resultou na oferta constante de educação física no 
seu currículo. Tendo em vista o crescimento da visibilidade esportiva, além de seu trabalho pedagógico, o colégio participou de todas as edições dos JES e dos Jogos da Primavera em sua $3^{\mathrm{a}}$ fase. A representatividade social e educacional de seu diretor o faria protagonista da cena educacional e esportiva sergipana, principalmente no seio dos Jogos.

Já no retorno dos Jogos em 1979, o Padre Carvalho, na condição de presidente do "Sindicato dos Diretores dos Estabelecimentos Particulares de Ensino", compôs a Comissão Geral dos "IV" Jogos da Primavera. O Arquidiocesano já assinalando a hegemonia que construiria, tornou-se "campeão geral" desta edição dos Jogos.

Cônscio da capacidade educativa do esporte e alerta ao crescimento da oferta do mercado educacional em Sergipe, o Padre Carvalho defendia uma concepção de escolarização do esporte:

Os Jogos da Primavera representam uma oportunidade muito boa para os alunos participantes das diversas competições desenvolverem suas habilidades esportivas que não são apenas físicas, mas um conjunto de qualidades necessárias ao desenvolvimento harmônico e integral da personalidade humana. Por isso considero uma maratona esportiva como a que atualmente está se desenvolvendo da mais importância para a educação da juventude. Por esta razão, como diretor do Colégio Arquidiocesano, sempre dei o máximo de apoio às atividades desportivas porque vejo nelas um excelente meio para o desenvolvimento completo dos alunos ${ }^{11}$.

Todavia, tal concepção ficaria restrita à retórica e, paulatinamente, perder-se-ia na oferta do esporte, sublimando a educação física, adquirindo centralidade mercadológica no projeto "educacional" do Arquidiocesano.

Ganha vulto a participação, ao longo de toda a década de 80, do Padre Carvalho como conselheiro do Conselho Estadual de Educação (CEE). Em 1986, o então Cônego, conselheiro José Carvalho de Souza emitiu um parecer sobre a "realização dos Jogos da Primavera", conforme havia sido indicado no ano anterior, por ocasião do "IX Simpósio Educacional" do CEE, que o Conselho se debruçasse sobre a validade do evento. O parecerista indicou dois problemas na realização dos Jogos: a suspensão das aulas, durante nove dias letivos e o atropelo na conclusão do ano letivo, com as provas finais e recuperações, quando "[...] muitos pais desejam seus filhos liberados para viajar, por ocasião das festas natalinas" (SERGIPE, 1986b, p. 2).

Diante desses "problemas", a indicação do relator foi: primeiro, que os "XII" Jogos, que se realizariam em 1987, fossem abertos com um "desfile com características olímpicas", sob a alegação do desconforto da avenida, do prejuízo da parca iluminação a partir das 18 horas, dos gastos desnecessários com carros alegóricos e bandas marciais, além de que parte da população não conseguia assistir aos aspectos essenciais da abertura, ou seja, a tocha e pira olímpica e juramento do atleta; segundo, a transferência da abertura para o Batistão com rituais olímpicos; terceiro, a realização das competições aos fins-desemana. A conclusão do parecer é uma defesa do CEE como instância regulatória dos bons ventos educacionais de Sergipe:

[...] este Colegiado, cumprindo o seu dever de zelar pelo aprimoramento pedagógico do nosso Sistema Educacional e atendendo às ponderações dos educadores, participantes do IX Simpósio Educacional e aos reclames de outros educadores, que põem os fins da educação acima de quaisquer outros interesses, oferece sua colaboração no sentido de aprimorar e tornar verdadeiramente olímpicos os Jogos da Primavera e de

Revista HISTEDBR On-line, Campinas, n.35, p. 108-125, set.2009-ISSN: 1676-2584 117 
compatibilizar a sua realização com a boa aprendizagem dos alunos e o transcorrer tranqüilo da vida das escolas (SERGIPE, 1986b, p. 5).

É possível compreender que, diante dos problemas sergipanos, os únicos óbices ao bom andamento dos Jogos fossem o "atropelo" do ano letivo e os obstáculos às viagens "natalinas e de férias" dos pais e alunos? A que pais e alunos, o CEE estava se referindo? As conclusões apontadas pelo parecer ratificavam o discurso dos jogos escolares em moldes olímpicos que, me parecem sintonizadas com a lógica espetacular que desconsiderava a realidade da escola pública e defendia a proposta de "esportivização", já em aperfeiçoamento, da escola privada.

No mesmo ano deste parecer, o conselheiro Antônio Fontes Freitas travou um tenso debate com o conselheiro Cônego Carvalho. O conselheiro Antônio Freitas transmitindo uma compreensão da educação física como fundamental à formação dos jovens e afirmando que as escolas particulares, imersas na dinâmica dos Jogos, não estavam ofertando educação física, substituindo-a pela "prática esportiva", concluiu que:

[...] as escolas, a título de formação de equipes de diversas modalidades têm deixado de oferecer Educação Física, formam uma equipe de "handball" que congrega uma dezena de alunos, incluindo os reservas, e os demais não fazem Educação Física, e isso deveria ser uma preocupação do Conselho Estadual de Educação, porque fere frontalmente toda a legislação pertinente, inclusive com prejuízos físicos para o desenvolvimento da criança e do adolescente. [...] O ideal em termos de formação do educando, seria que a Educação Física levasse à descoberta de valores nas práticas que realiza, mas não selecionar um grupo, formando uma elite dentro da própria escola, deixando de fazer Educação Física, inclusive criando um mercado de profissionais dentro das instituições de ensino em termos desportivos (SERGIPE, 1986a, p. 9$10)$.

Em contrapartida, segundo o secretário-redator da ata, o Cônego Carvalho afirmou que:

[...] acredito que as escolas que levam a sério os esportes, estão fazendo um bem imenso aos atletas, pelo fato do mérito enorme de modalidades que oferecem, inclusive pelo fato de estarem sendo a base das seleções estaduais, quando participa de jogos interestaduais, como é o caso do Colégio Arquidiocesano, onde as equipes do Estado estão tendo suas bases com os atletas daquele Colégio e disse, que não é uma coisa que o estabelecimento faz só por si, também o faz para o Estado que se beneficia e, os alunos que não estão integrados em nenhuma equipe têm sua Educação Física normal. Agora é sabido, acrescenta, que antes do aluno entrar na quadra do Ginásio para jogar 'volley-ball', 'handball', etc. só o aquecimento que faz, substitui de longe qualquer aula de Educação Física sistemática, e depois, essas aulas de treinamento por semana, estão indo muito além que aquelas três aulas regulamentares (SERGIPE, 1986a, p. 10).

O debate é ilustrativo da função de um órgão público como o CEE. Enquanto uns conselheiros defendiam a legislação como meio de garantia à formação dos estudantes, ainda que pela via meramente burocrática, outros defendiam as brechas da legislação como legitimidade às práticas mercantis da escola particular. Reportar-se aos alunos como atletas, garantindo aos excluídos a "educação física normal", que o "aquecimento" 
substituía qualquer aula de educação física, bem como que o Arquidiocesano estaria prestando um grande serviço ao estado de Sergipe, quando seus "atletas" o representavam nacionalmente, me parecem demonstrar o que o CEE era (ou continua sendo?): um órgão público legitimador e garantidor dos benefícios da rede privada de ensino.

O Arquidiocesano, assim como outros colégios particulares, tornaram-se grandes vencedores de modalidades esportivas dos Jogos por montarem uma estrutura profissional para o trato com o esporte escolar: grandes ginásios e piscinas; material esportivo de alta qualidade; professores especialistas em cada modalidade esportiva (lembrando que, geralmente, o sujeito não era contratado como professor de educação física, mas técnico de voleibol, basquetebol, futsal); contratação de "alunos-atletas" de escolas públicas em troca de bolsas de estudo e facilidades no aproveitamento escolar. Afora essa estrutura, a dinâmica interna da escola sustentou a segregação entre alunos de educação física e alunos das "escolinhas esportivas" ${ }^{12}$. Estes pagavam taxas-extras para praticarem as modalidades escolhidas que, por lei e sensibilidade educacional, deveriam compor o currículo da educação física. Tais taxas seriam canceladas se os alunos conseguissem ascender às "turmas de treinamento" para integrarem as equipes da escola. As aulas de educação física, além da segregação financeira, eram "aulas de punição", desagradáveis e sem objetivos claros, a não ser a prática rotineira e obrigatória do "fazer pelo fazer". Toda a organização da educação física de $1^{\mathrm{a}}$ à $4^{\mathrm{a}}$ série do ensino fundamental era montada de maneira a que os alunos fossem "iniciados" nas modalidades mediante um "rodízio" de práticas esportivas. Impunha-se, de modo sub-reptício, que o aluno deveria procurar (entenda-se pagar!) os esportes ou as "escolinhas" que melhor lhe aprouvesse.

Após o fim dos Jogos em 1995, o Arquidiocesano, assim como outros colégios, incentivaram o funcionamento do esporte amador, tomando por referência, vínculos com federações esportivas a fim de realizarem eventos que substituíssem os Jogos da Primavera. Com isso, em 1999, o Arquidiocesano fundou o "Arquiclube", instituição que se utilizava dos próprios alunos, professores e estrutura física e material da escola, inclusive a própria aula de educação física, para seleção e preparação de futuros "atletas". Estes "atletas" passaram a disputar as competições estaduais promovidas pelas federações esportivas situadas na capital (SANTANA e RIBEIRO, 2003).

As escolas particulares de Aracaju, desconsiderando a educação física como componente curricular, sob a fachada do esporte como fundamento da formação dos jovens, mercantilizaram a oferta do esporte, tornando-o, ao lado dos resultados do Vestibular, o grande chamariz de consumidores dos seus serviços educacionais. Castro Junior (2005) investigou o uso mercantil da educação e do esporte em Sergipe, por meio de discursos e imagens publicitárias. Detectou que a oferta de esportes, através da exibição das estruturas físicas esportivas, dos seus campeões e resultados, funcionando com os princípios mercadológicos de rendimento e produtividade, disseminavam no imaginário e associavam na memória social a imagem e a idéia da "escola vencedora".

Por este prisma, as escolas absorveram os princípios que regem os clubes esportivos e, tão somente, deram vazão ao receituário espetacular do capitalismo internacional. A escola assumiu-se de vez, uma empresa de serviços educacionais. As estratégias utilizadas, similares a uma "esportivização", revelaram como se definem ações competitivas para se firmar nos seus "nichos" de mercado. Entendo, com base em Pablo Gentili (1996), que a "esportivização" da escola se assemelha ao que se denomina de "mcdonaldização" da escola: sistemas de controle e premiação (quem mais produz, mais ganha); oferta com publicidade em profusão; treinamento rápido e eficiente; ambiente limpo e produtivo; pessoas felizes e satisfeitas. As semelhanças não são coincidências, nem são forçadas: há um controle na oferta e seleção do melhor "produto" ou melhor "atleta"; 
existem prêmios para quem melhor "produz" para a escola (os "alunos-atletas" ganham notas, os "professores-treinadores" ganham uma sobrevida e se asseguram mais um ano no emprego); executa-se um treinamento rápido e eficiente do "atleta" baseando-se na seleção inicial, nas "escolinhas", e do "treinador", já que muitas escolas contratavam leigos com "experiência esportiva" para serem técnicos (treinar um professor é tão simples quanto treinar um "preparador de hamburguer"); existem piscinas e ginásios irrepreensíveis, limpos, saudáveis e eficientes, onde os alunos ("compradores") podem ser "felizes".

Defendo que, a "esportivização" da escola é a síntese educacional da sociedade do espetáculo, qual seja, uma civilização pautada pela mercantilização das relações sociais como imagens (DEBORD, 1997). Como o espetáculo é a afirmação de toda a existência humana como simples aparência, os Jogos da Primavera e as escolas assumindo-se como "clubes" ratificaram a aparência como ápice da mistificação do real, limitando a possibilidade de pedagogização do esporte voltado à formação dos jovens, impingindo-lhes o papel de "consumidores" da oferta esportiva e "trabalhadores" do marketing esportivoeducacional da escola.

\section{III - Do fim dos Jogos ao "novo" começo:}

Em meio à hegemonia das escolas particulares nos Jogos e a utilização do esporte como principal "produto educacional" das mesmas, qual a direção dada à educação física e às perspectivas de escolarização do esporte em Sergipe?

Após o fim dos Jogos em $1995^{13}$, o governo de Albano Franco tentou incrementar a educação e a área de educação física. Pela primeira vez, foram abertas turmas do Ensino Médio em todos os municípios sergipanos. Instituiu-se, em convênio com a UFS, o Projeto de Qualificação Docente (PQD) que objetivava conceder formação superior aos professores de educação básica do interior que somente possuíam habilitação técnica, inclusive professores de educação física. Desenvolveu-se um projeto de construção de quadras esportivas e cobertura das quadras existentes nas escolas públicas que modificaram a paisagem da capital. São avanços pequenos, contudo significativos que ainda precisam ser analisados em seus impactos sociais.

A partir de 1997, a Coordenação de Educação Física, da Secretaria de Estado da Educação, do Desporte e Lazer (COEF/SEED), sob a coordenação do professor Gilson Dória Leite Filho, buscou dinamizar a área e dar conseqüência ao texto da LDB n. ${ }^{\circ}$ 9.394/96 que decretou a educação física como componente curricular da educação básica, inserida no projeto pedagógico da escola. A equipe da COEF tentou elaborar uma proposta de educação física para a rede estadual, que resultou na Portaria $n .^{\circ} 1.251 / 99$, normatizando a educação física, definindo a cultura corporal como seu objeto, mesmo mesclando-a com a proposta do esporte educacional (SERGIPE, 1999). Além da Portaria, publicaram o livro "Subsídios aos Conteúdos da Educação Física" visando à orientação dos professores acerca das múltiplas possibilidades do acervo da cultura corporal a serem escolarizados (SERGIPE, 1998). Propuseram e realizaram os "Encontros Estaduais de Educação Física" que promoveram profícuos debates, mini-cursos e produziram coletâneas de trabalho que veicularam artigos e ensaios de professores da rede, socializando o conhecimento, produzido com base nas experiências pedagógicas ${ }^{14}$.

Não obstante a superficialidade dos documentos e a miscelânea de concepções teóricas antagônicas, as iniciativas da COEF demonstraram existir condições de se pensar a educação física em Sergipe para além dos Jogos, tentando inclusive reorganizar jogos escolares sob outras bases. Contudo, as mudanças de governo, novamente, solaparam as propostas em curso e o retorno do governador João Alves Filho trouxe consigo, mais um 
retorno dos Jogos da Primavera, desta feita, como Lei a ser seguida pelos executivos vindouros (SERGIPE, 2004).

Essa nova fase dos Jogos ( $4^{\text {a }}$ fase?) não é o foco desse trabalho, tendo em vista que o objetivo aqui era demonstrar o recrudescimento da "esportivização" da escola, em meio aos jogos escolares. De igual modo, é perceptível que tal processo não sofreu alteração, dado que os últimos resultados dos Jogos da Primavera, entre 2004 e 2007, marcaram novas quatro vitórias do Colégio Arquidiocesano.

Somada a este quadro, a partir de 2003, a TV Sergipe, afiliada da Rede Globo de Televisão, descobriu o filão do esporte estudantil e passou a promover campeonatos envolvendo escolares: a "Copa TV Sergipe de Handebol" e as "Olimpíadas Escolares TV Sergipe". A entrada de emissoras de TV, não mais como noticiadores do espetáculo esportivo, mas agenciadores do espetáculo, estreitou uma nova relação entre política, educação e cultura. Esse novo tipo de apoio ao esporte continua dando fôlego à "esportivização" da escola, conforme se observa no slogan do Colégio Amadeus em 2007: "o campeão do vestibular agora é campeão das Olimpíadas Escolares TV Sergipe".

Em meio a essa fase de "treinamento", as condições de "preparação" dos que erigiram a "esportivização" da escola foram e são mais sólidas e parecem consolidar a compreensão do esporte como somente rendimento, somente mercadoria. Por essas questões, entendo que continuamos, no século XXI, sob a vigência da sociedade do espetáculo, gerada no século anterior, na qual o esporte e a escola são geridos pelos ditames da produtividade e eficiência e os homens são prioritariamente consumidores, e ocasionalmente cidadãos. Contudo, constatei que os professores conseguiram, baseados em suas experiências, e ao longo das últimas décadas, demarcar suas posições, construir suas práticas e, ainda que em esforços isolados, mostraram que é possível permanecer em tensão constante, lutando todos os dias pela dimensão da escola que pedagogiza o esporte e o torna fundamental à formação da juventude (DANTAS JUNIOR, 2008).

\section{Por fim...}

Ao me propor discutir os Jogos da Primavera em Sergipe não pretendia narrar sua história, realizações, resultados, sujeitos e feitos históricos. A intenção foi compreender os Jogos como um dos ícones da "esportivização" da escola em Sergipe, buscando suas dimensões, representações e contradições.

Refletindo a história por categorias de Thompson (2001), é possível entender que o processo de "esportivização" da escola se sustentou em "mudanças involuntárias", próprias do avanço histórico, mediante o desenvolvimento científico e tecnológico das comunicações, das formas de organização do conhecimento escolar, fundamentalmente da força imagética refletida pelos avanços do esporte, do ponto de vista material ao humano. Tornou-se impossível, a partir de fins do século XIX, ser indiferente à educação escolarizada e ao esporte, que formataram todos os afazeres cotidianos da humanidade.

Durante os 30 anos em que os Jogos da Primavera se desenvolveram, se fortaleceram, se enfraqueceram, se reergueram e se enraizaram na memória social sergipana, quais as "congruências" palpáveis? Os Jogos surgiram em meio à ditadura, com um caráter festivo e uma concepção de esporte como fundamental à formação dos jovens, tanto em seus aspectos utilitaristas da saúde quanto moralistas da formação do caráter com cores nacionalistas. Todavia, não se deve incorrer no equívoco de alinhar automaticamente a realização de jogos estudantis e o incentivo ao esporte com os interesses "conspiradores" dos militares no poder. Já as transformações dos Jogos na década de 70 corroboraram o anseio pelo "Brasil Grande" que deveria se destacar, inclusive, nos palcos esportivos. Com a criação dos JEBs instituiu-se uma "esportivização" da escola que não logrou êxito, 
especialmente em Sergipe, com os "Jogos Estudantis Sergipanos", devido à falta de estrutura física e de recursos humanos qualificados. Essa proposição oficial transmutou-se, a partir de 1979, em instrumentalização e personalização política dos Jogos da Primavera, ampliou e contribuiu, visivelmente, com o alargamento do abismo entre escolas públicas e privadas, bem como resultou na "esportivização" da escola, que mercantiliza a educação e advoga vitórias esportivas (inclusive na "corrida" do vestibular) como parâmetro para a "boa escola".

Que "contradições" foram geradas na tensão entre as normas e interesses oficiais e a experiência dos professores, alunos, diretores e dirigentes? Da prática pedagógica baseada na experiência como "atleta" à prática pensada, refletida e assentada em preceitos pedagógicos, sólidos ou em ebulição, a ação dos professores de educação física foi cindida entre "treinadores" e "professores". Estes, em meio à euforia dos Jogos, construíram práticas pedagógicas que dão sustentação para continuarmos pensando, hoje, nas possibilidades de "escolarização" do esporte. Os alunos - que vivenciaram os Jogos em todas as suas contradições; da escolha à exclusão, das quadras às arquibancadas, dos sonhos aos pesadelos - souberam inserir-se na prática e vivenciar experiências que os guiaram à profissionalização (no caso dos que se tornaram atletas de alto nível ou professores de educação física) ou mesmo à simples vivência feliz da prática esportiva. Os diretores souberam vincular suas imagens de "incentivadores do esporte" à escola, principalmente quando "campeões" dos Jogos, estabelecendo medalhas e troféus como parâmetros da formação da juventude sadia, disciplinada e pronta aos desafios da sociedade competitiva (DANTAS JUNIOR, 2008).

As proposições do Estado, quanto à instrumentalização política, e do mercado, quanto à lógica do comercializável, estiveram sempre em confronto com as ações dos indivíduos e as resistências construídas. Entendo que as interpretações do uso da educação física como "razão de Estado" observaram a área por lentes externas à sua dinâmica interna, bem como assentaram-se em vínculos ideológicos os quais fizeram a crítica mais política que científica ou histórica. As ações oficiais engendradas pela ditadura para a educação física, mais atenderam a demandas da sociedade e anseios dos professores do que representaram políticas de acomodação e dominação. Longe de querer pintar com "cores suaves" e abrandar as intencionalidades e ações perversas da ditadura, busco ressaltar seu entorno nebuloso, sua violência e irracionalidade sem, contudo, obscurecer os avanços notáveis provocados na sociedade brasileira. De igual modo, pretendo não incorrer na dicotomia das "trevas" da ditadura e o momento "colorido" (sem trocadilhos) da redemocratização nacional. Entulhos da ditadura continuam a ocupar espaço social, mas também avanços continuam a existir. Na educação física não tem sido diferente.

O retorno dos Jogos da Primavera tão somente ratificam toda uma dimensão de "esportivização" da escola que sustenta a submissão da rede escolar aos princípios espetaculares. Por estarmos sujeitos à espetacularidade vigente não podemos esquecer, entretanto, que não há unilateralidade nessa relação: existem determinações, mas existem oposições. Ao longo do processo de "esportivização" da escola, em meio ao fortalecimento dos Jogos em Sergipe, os sujeitos materializaram as múltiplas tensões e a pluralidade de intenções dessa relação. As tensões são reais e estão em curso, conseqüentemente o processo histórico não se encerrou. 


\section{Referências:}

BARROS, J. D. O projeto de pesquisa em História: da escolha do tema ao quadro teórico. Petrópolis: Vozes, 2005.

BOCCARDO, L. M. Representação social da mulher brasileira na atividade físicodesportiva: da segregação à democratização. 1998. 320 f. Tese (Doutorado em Educação Física) - Programa de Pós-graduação em Educação Física, Universidade Gama Filho, Rio de Janeiro.

BRACHT, V. Educação física e aprendizagem social. Porto Alegre: Magister, 1992.

BRASIL. Ministério da Educação e Cultura. Departamento de Educação Física e Desportos. Jogos Estudantis Brasileiros: Regulamento geral. Brasília: [s.n.], 1969.

Secretaria de Educação Física e Desportos. Portaria n..$^{\circ}$ 001, de 7 de abril de 1982. Estabelece normas para organização e funcionamento do Desporto Escolar. Disponível em: <http://www.prolei.inep.gov.br>. Acesso em: 13 nov. 2006.

CASTRO JUNIOR, C. A. S. Esporte e espetáculo: as imagens dessa união nas escolas particulares de Aracaju/SE. 2005. 117 f. Monografia (Licenciatura em Educação Física) Departamento de Educação Física, Universidade Federal de Sergipe, São Cristóvão.

COLETIVO DE AUTORES. Metodologia do ensino de educação física. São Paulo: Cortez, 1992.

CONNERTON, P. Como as sociedades recordam. Tradução Maria Manuela Rocha. 2. ed. Oeiras: Celta, 1999.

DANTAS JUNIOR, H. S. Estado, Educação e Hegemonia: reflexos da Pedagogia Experimental na Educação Física em Sergipe (1947-1951). 2003. 151 f. Dissertação (Mestrado em Educação) - Núcleo de Pós-graduação em Educação, Universidade Federal de Sergipe, São Cristóvão.

. Da "escolarização do esporte" à "esportivização da escola": tradição e espetáculo nos Jogos da Primavera de Sergipe (1964-1995). 2008. 333 f. Tese (Doutorado em Educação) - Programa de Pós-graduação em Educação, Faculdade de Educação, Universidade Federal da Bahia, Salvador.

DEBORD, G. A sociedade do espetáculo. Rio de Janeiro: Contraponto, 1997.

FIGUEIREDO, A. História política de Sergipe 5: 1962-1975. Aracaju: [s.n.], [198-].

GENTILI, P. Neoliberalismo e educação: manual do usuário. In: ___ SILVA, T. T. (Org.). Escola S. A. Brasília: CNTE, 1996. p. 9-49.

HALL, S. A identidade cultural na pós-modernidade. 10. ed. Rio de Janeiro: DP\&A, 2005.

NERY, M. A. A. M. Políticas educacionais em Educação Física na década de 1990: uma análise do contexto sergipano. 2002. 81 f. Monografia (Licenciatura em Educação Física) - Departamento de Educação Física, Universidade Federal de Sergipe, São Cristóvão.

SANTANA, A. J.; RIBEIRO, S. D. D. As influências mercadológicas num determinado fenômeno esportivo - basquetebol - alterando sua forma e conteúdo, na realidade escolar sergipana. Caderno do Estudante, São Cristóvão, v. 3, p. 83-96, 2003.

SANTOS, R. C. F. A. Teoria e prática na educação física: o que se (re)produz na educação física em Sergipe (1998-2003). 2003. 85 f. Monografia (Licenciatura em Educação Física) - Departamento de Educação Física, Universidade Federal de Sergipe, São Cristóvão.

SAVIANI, D. Pedagogia histórico-crítica: primeiras aproximações. 5. ed. Campinas: Autores Associados, 1995. 
SERGIPE. Lei n. 5.493, de 21 de dezembro de 2004. Institui os "Jogos da Primavera", como evento desportivo a ser realizado anualmente, e dá providências correlatas. Disponível em: <http://www.seed.se.gov.br>. Acesso em: 5 jan. 2005.

. Secretaria de Estado da Educação e Cultura. Conselho Estadual de Educação. ATA da sétima sessão plenária do CEE. Livro de Atas do Plenário. Aracaju: 1986a. 11 p. Datilografado.

• Parecer $\mathbf{n}^{\mathbf{0}}$ 188/86/CEE, de 16 de outubro de 1986b. Indica normatização de realização dos Jogos da Primavera. Relator: José Carvalho de Souza.

Secretaria de Estado da Educação, do Desporto e Lazer. Portaria n. ${ }^{\mathbf{1}}$ 1.251, de 17 de maio de 1999. Normatiza o ensino de Educação Física na Rede Estadual de Ensino. - Coordenadoria de Educação Física. Subsídios aos conteúdos da

Educação Física. Organização Gilson Dória Leite Filho et al. Aracaju: J. Andrade, 1998. TABORDA DE OLIVEIRA, M. A. Educação física escolar e ditadura militar no Brasil (1968-1984): entre a adesão e a resistência. Bragança Paulista: Editora da Universidade São Francisco, 2003.

THOMPSON, E. P. A miséria da teoria ou um planetário de erros: uma crítica ao pensamento de Althusser. Rio de Janeiro: Zahar, 1981.

As peculiaridades dos ingleses e outros artigos. Campinas: UNICAMP, 2001.

VAGO, T. M. A Educação Física na cultura escolar: discutindo caminhos para a intervenção e a pesquisa. In: BRACHT, V.; CRISÓRIO, R. (Org.). A Educação Física no Brasil e na Argentina: identidade, desafios e perspectivas. Campinas: Autores Associados; Rio de Janeiro: Prosul, 2003. p. 197-221.

\footnotetext{
"Doutor em Educação (UFBA). Professor Adjunto da Universidade Federal de Sergipe. Coordenador do Grupo de Estudos e Pesquisas "História, Sociedade e Educação no Estado de Sergipe" (NPSE/UFS). E-mail: hamilcarjr@hotmail.com.

${ }^{1}$ A cidade de Aracaju foi projetada em 1854 com ruas em linhas retas e cruzamentos a cada 100 metros pelo engenheiro Sebastião José Basílio Pirro, perfazendo a figura de um imenso tabuleiro de xadrez, adjetivado para posteridade de "quadrado de Pirro".

${ }^{2}$ Desde as indicações prescritas no "Diagnóstico de Educação Física/Esporte no Brasil", coordenado por Lamartine Pereira da Costa em 1971, acerca da necessidade de investimento na educação física pelo viés do esporte escolar, foram realizadas nove edições dos Jogos Olímpicos. Dos Jogos Olímpícos de Munique (1972) aos Jogos de Atenas (2004), o aumento do número de medalhas brasileiras foi significativo, mas muito distante de sequer aproximar-se de uma potência olímpica.

${ }^{3}$ Memória é um artefato simbólico de representação das relações sociais que se constrói pela experiência. Duas práticas sociais de solidificação da memória são as de "incorporação" e "inscrição". A incorporação se refere à comunicação entre corpos presentes - aperto de mãos, abraços, sorrisos, palavras dirigidas - que se processam enquanto os corpos estão se comunicando. Já a prática de inscrição alude às ações intencionais de capacitação e conservação de informação, muito depois do organismo humano ter deixado de informar fotografias, fitas de áudio, imprensa. Na esfera cultural, o cinema, a literatura, a música e a televisão seriam práticas de inscrição, enquanto o teatro seria uma prática de incorporação pois de comunicação direta entre os artistas e espectadores. As práticas educacional e esportiva exigem os dois tipos de ação, ou seja podem ser inscritas e/ou incorporadas. Os Jogos, portanto, se consubstanciam como práticas enraizadas, por incorporação e inscrição, na memória social sergipana. (Cf. CONNERTON, 1999).

${ }^{4}$ Tomando por princípio que o recorte temporal de um objeto estabelece nexo central com a construção da problemática, o recorte do objeto, qual seja, o processo de "esportivização da escola", assenta-se na segunda metade do século XX. Contudo, como recortes temporais vinculam-se a recortes espaciais, tomo por base que sendo os Jogos da Primavera em Sergipe o locus de investigação desse processo, uma delimitação temporal de análise das fontes situa-se entre 1964, início da tradição dos Jogos em Sergipe, e 1995, ano de seu segundo encerramento em meio à materialização da "escola esportivizada". (Cf. BARROS, 2005).

${ }^{5}$ Adoto o termo representação a partir do conceito de representação cultural de Stuart Hall. Para o autor, as práticas e sentidos sociais são construções históricas vividas que só têm significância quando produzem sentido, produzem identificação, pertencimento, daí que construímos nossas identidades como representações culturais. (Cf. HALL, 2005).
} 


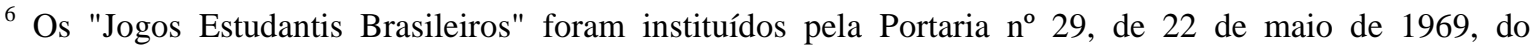
Ministério da Educação e Cultura, sendo realizados pela primeira vez neste mesmo ano na cidade de Niterói, no estado do Rio de Janeiro. (Cf. BRASIL, 1969).

${ }^{7}$ Necessário destacar a fundação das duas principais redes de televisão de Sergipe nessa década. A TV Sergipe, filiada à Rede Globo, em 1971, e a TV Atalaia, em 1975, filiada à Rede Tupi, posteriormente à Bandeirantes, SBT e, hoje, Rede Record.

${ }^{8}$ Nas três primeiras edições dos Jogos, de 1964 a 1966, o campeão geral foi o Colégio Tobias Barreto, então escola particular de propriedade do professor Alcebíades Melo Villas-Boas. O Colégio Tobias Barreto foi comprado pelo Governo do estado de Sergipe em 1969 tornando-se escola pública. O Atheneu fora campeão dos Jogos em 1967 e voltaria a ser campeão novamente nos anos de 1980 a 1983. Juntamente com o Colégio Presidente Vargas (campeão dos Jogos em 1984), seriam as duas únicas escolas públicas campeãs dos Jogos da Primavera. Desde então apenas duas escolas conquistaram a competição: o Colégio Unificado (1985, 1986 e 1989) e o Colégio Arquidiocesano Sagrado Coração de Jesus (1979, 1987, 1988, 1990 a 1995, 2004 a 2009).

${ }^{9}$ Projetos e Pareceres armazenados no Conselho Estadual de Educação.

${ }^{10}$ Dos "Clubes" que se inscreveram nos "IX" Jogos, todos eram escolas públicas: Clube Escolar 17 de Março; Clube Escolar Governador Augusto Franco; Clube Escolar José Rollemberg Leite; Clube Escolar Olavo Bilac; Clube Escolar Presidente Castelo Branco; Clube Escolar Presidente Costa e Silva; Clube Escolar Prof. Acrísio Cruz; Clube Escolar Prof. Arício Fortes; Clube Escolar Ruy Barbosa; Clube Escolar Santos Dumont (Cf. DANTAS JUNIOR, 2008).

${ }^{11}$ CÔNEGO Carvalho elogia a organização. Gazeta de Sergipe, Aracaju, p. 8, 22 out. 1982.

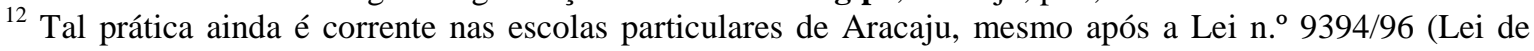
Diretrizes e Bases da Educação Nacional) garantir a obrigatoriedade da educação física como componente curricular da Educação Básica. Radicalizou-se a separação entre educação física e esporte e enraizou-se, culturalmente, a lógica mercadológica das "escolinhas esportivas". Como se posiciona o CEE diante dessa questão? Esse é um fato a investigar e explorar.

${ }^{13}$ O fim dos Jogos em 1995 deveu-se a uma decisão ousada e administrativamente bem justificada pelo, então Secretário de Educação, Luiz Antônio Barreto: "Eu propus trocar os Jogos da Primavera que não era uma coisa nossa, era um pastiche, um decalque, uma coisa postiça à nossa história cultural e estudantil e organizar os Jogos Estudantis. Os particulares que fizessem os deles e a rede pública que o fizesse os dela. Pra quê? Pra você assumir daquele momento em diante, melhorar as quadras, criar áreas de campos de pelada junto às escolas, investir na preparação de atletas, organizar equipes, treinar melhor os professores, dar a eles melhores condições de trabalho, enfim chamar atenção para que a educação física interpenetrasse na escola em todos os ambientes do projeto pedagógico. Então, eu assumi a responsabilidade de estabelecer uma nova visão sobre o esporte, o desporto escolar, e eu tinha de fazer estancando aquela sangria que era os Jogos da Primavera. Porque o Estado, que passava o ano inteiro sem fazer nada pelo desporto escolar, chegava no meio dos Jogos da Primavera investia tudo, reunia tudo, dizia tudo e cada um procurava mostrar sua equipe do melhor modo, mas era, na verdade, uma passarela montada para as escolas particulares que levavam vantagem. Todas as vantagens, porque tinham liberdade pra tudo, enquanto nós tínhamos regra pra tudo e tinham todas as condições, enquanto nós não tínhamos nenhuma condição" (Luiz A. Barreto apud DANTAS JUNIOR, 2008, p. 231). Ainda que discordante das justificativas do Secretário, que tão somente ratificam a lógica esportiva dentro da escola, é preciso reconhecer a sua ousadia ao impactar as raízes culturais e promover um debate acerca dos rumos da educação física em Sergipe.

${ }^{14}$ Como parte da análise desse processo em Sergipe e dos esforços da COEF no período, indico a leitura de Nery (2002) e Santos (2003).

Artigo recebido em: 30/08/09

Aprovado para publicação em: 30/09/09 